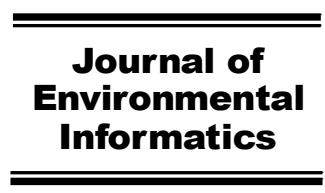

www.iseis.org/jei

\title{
Design of Closed Loop Supply Chain of Wood Plastic Composite (WPC) Industry
}

\author{
N. Doustmohammadi and R. Babazadeh* \\ Faculty of Engineering, Urmia University, Urmia, West Azerbaijan Province 5756151818, Iran
}

Received 06 September 2017; revised 15 March 2018; accepted 07 April 2019; published online 15 August 2019

\begin{abstract}
Substituting woody products with wood plastic composite (WPC) products has attracted many interests in recent years. This article seeks to provide an approach to construct a reliable network of closed loop supply chain (CLSC) facilities for WPC industry. The WPC products could be thoroughly collected and recycled and used as raw material for producing new products. In this paper, a mathematical model has been developed that involves deciding direct and reverse flows in the supply chain. The proposed model is mixed Integer linear Programming (MILP) one which minimizes total costs including opening facilities, production, distribution, collection and recycling costs in the forward and reverse sides of the CLSC. The proposed model is applied in a real case of production WPC doors. Sensitivity analysis is performed to evaluate the behavior of the model respect to the changes of the important parameters. The acquired results confirm the applicability of the proposed MILP model in designing real CLSCs.
\end{abstract}

Keywords: closed loop supply chain, wood plastic composite, mixed integer linear programming

\section{Introduction}

With the rise of global market competition, supply chain management has become one of the most important issues for organizations. Supply chain management involves all processes of manufacturing and supplying goods, from raw materials to final customers. In other words, the whole supply chain from extraction of materials to the end of the useful life of the product. Issues such as product diversity, short life cycle of products, outsourcing, business globalization and rapid growth in information technology have increased the complexity of supply chain management (Lee, 2002).

In the classical definition of supply chain management, it is considered as a line by moving goods from suppliers to manufacturers, and going to wholesalers and retailers and it takes all the way to reach consumers through these distribution channels. Todays, due to environmental, social and economic advantages and also governmental lows, companies consider collection and recycling the used products besides production of new products. Therefore, traditional supply chains have changed to closed loop supply chains (CLSC) (Cruz-Rivera and Ertel, 2009). The concept of closed loop supply chain design is presented with concepts such as product recycling, recycling, or reuse of products. In universal, the closed loop supply chain consists the determination of the number of collection centers, the determination of the location and capacity of the

${ }^{*}$ Corresponding author. Tel.: +98 44 32972854; fax: +98 4432773591. E-mail address: r.babazadeh@urmia.ac.ir (R. Babazadeh).

ISSN: $1726-2135$ print/1684-8799 online

(C) 2020 ISEIS All rights reserved. doi:10.3808/jei.201900419 collection centers, the retrieval and reuse of stored inventory at each site (Kara et al., 2010).

Cutting too much trees in today's world quickly destroys animals and plant species and drains land from oxygen sources. One of the solutions to this problem is the invention of composite wood. Composite wood is a wood substitute; it is made of broad-leaved waste and polymeric materials. This new material has the appearance and quality of many rare wooden species, while it is environmentally friendly. It should be noted that the manufacturer of wood plastic composite doors annually prevents the destruction of three million trees. In addition, composite doors have many advantages that can be anti-corrosion resistance, high strength, anti-flammability, and superb facade of composite doors (Moyes, 2000). The WPC products could be thoroughly recycled and used as raw material in producing new WPC products. Therefore, designing the network of CLSC is critical in this area. This attempt will reduce the total costs of the CLSC network and will improve the commerciality of WPC industry.

By producing WPC products, the amount trees cut for producing different products are remarkably reduced. Therefore, because of the importance of wood plastic composites, in terms of environmental protection, the design of closed-loop supply chain network for WPC industry is very important. Iran is categorized as arid and semi-arid areas and decreasing cutting trees in highly supported by government and practitioners. In this paper, we have designed the CLSC network of WPC industry in Iran. The raw materials used to make WPC doors include: Wood flour and Polymer materials (such as polypropylene).

Wood flour used in this product can be purchased or wood waste can be used as raw material. In this study, the waste ma- 
terials consist of waste from the same product in the production line of the plant or goods delivered to the hybrid distributioncollection centers after being used.

The products manufactured in the hybrid manufacturingrecycling centers are two types: Composite doors and windows, which is used for building applications and has a resin like plastic and properties such as wood and more solid than ordinary wood. Therefore, in this research two type of raw materials and two type of final products are considered.

In this research, a mixed-integer linear programming (MILP) model is developed to construct the CLSC network for WPC industry. The proposed model is aimed to minimize the total costs including production, transportation, collection, and recy-cling costs subject to various constraints including the number of factories to be built and limitations of the number of goods after use as waste and restrictions related to the storage capacity of the products and related waste, and demand satisfaction constraint. The proposed model is applied in a real case in Iran.

To the best of our knowledge, there is no research paper in the literature addressing the design of CLSC for WPC industry. The goal of this research is to find the optimum number and locations of WPC production and recycling centers, distribution and collection centers and optimum material flow transported in forward and reverse sides of the CLSC network.

This paper will be constructed by the following sections. In the next section, the literature review is presented. In Section 3 , the problem is described and formulated through developing a MILP model. Section 4 describe the case study and the results of application. Section 5 presents conclusion and some managerial implications.

\section{Literature Review}

One of the first models presented in supply chain management is a model that Hansmann and Hess (1960) developed, which introduced a model based on linear programming approach using linear cost of decision variables. Then, Van Lanzenauer (1970) developed the model of Hansmann and Hess for multistage and multi-product manufacturing systems and made decisions with regard to capacity constraints. Govindan et al. (2015) presented a comprehensive review in the area of reverse logistics and closed-loop supply chains to explore future researches. They investigated different structures and models developed for CLSCs optimization.

In connection with the closed loop supply chain management, Fleischmann et al. (2001) provided a general model for designing these types of networks. They considered direct and reverse flows as part of the definition of the distribution and recovery network in an optimal mode. They also used MILP technique to model the problems that exist in traditional warehouses. Fleischmann et al. (2003) developed a model of inventory control and simulation in an integrated CLSC, and, in order to measure their operational capability, they provided other alternatives as a source of spare parts that could better serve the purpose of network services. Chen and Lee (2004) provided a production and distribution planning model that is multi-stage, and multi-product. They developed a two-stage fuzzy decision-making method for comparing suppliers in the supply chain.

In a study on closed loop supply chain, Beamon and Fernandes (2004) presented a model in which a model for the production of original equipment was proposed that could be used to produce both new products and recycled products. Sheu et al. (2005) in their research on closed loop supply chain presented a multi-objective optimization model that aims to maximize net profit and minimize environmental impacts for direct supply chain and reverse supply chain.

Uster et al. (2007) developed a direct supply chain loop chain to determine the collection and retrieval centers. All direct and reverse currents were optimized in this design. Listes (2007) proposed a model in which the direct supply chain and the reverse supply chain were taken as a packet. He used the branching and boundary method to analyze the model to solve problems of very large size. Ramudhin et al. (2010) studied the supply chain, consisting of suppliers, contractors, manufacturers, distribution centers, and customers. In this paper, a complex integer programming was proposed to design the supply chain network. Their paper has two objective functions based on optimization of total costs and greenhouse gas emissions.

Paksoy et al. (2010) presented a mathematical model to design a closed loop supply chain network with the aim of optimizing total costs and the cost of carbon emissions. Paksoy et al. (2011) in another study, examine the operational and environmental performance, in particular the operations related to the transportation of operations, in the closed loop. It also models the supply chain with linear programming method.

Chaaban et al. (2012) studied a closed loop supply chain network consisting of suppliers, production centers, recycling centers, and customer centers. In this paper, to design a sustainable supply chain, two objective functions including minimization of the usual supply chain costs, and the cost of greenhouse gas emissions are optimized. In another study by Özkır and Başligil (2013), the proposed model consists of three objective functions. The first objective function is to maximize the level of satisfaction with business. The second goal is to maximize customer satisfaction, and ultimately the third objective function is to maximize the entire profit function in the closed loop supply chain. The purpose of the proposed model is to find the optimal location of the facilities in the CLSC and determine the optimal amount of transport, production, and optimal purchase value. Talaei et al. (2016) in a study on a CLSC proposed a MILP model that aims to minimize total costs. The objective of the supply chain is to determine the locations of the sites to the cen-ters of production and reconstruction, distribution and collection centers. They have applied their proposed model in an electronic industry. Hassanzadeh Amin et al. (2017) have studied the CLSC for recycling tires. The objective function of the model is the type of maximization of profit. This model includes several types of products, raw material suppliers, factories, retailers, and markets for satisfying the demands. Also, to calculate net present value, the decision tree method is used for sources with uncertainty. 


\section{Description of the Proposed Model}

The proposed model for designing CLSC network for WPC industry is a model for a multi-site, multi-layer network, single period and several products. Figure 1 shows the proposed closed loop supply chain structure. In this figure, straight lines represent the flow of goods, and dash lines represent the reverse flow of materials for collection and recycling purpose. According to Pishvaee et al. (2009), constructing hybrid manufacturing and recycling or hybrid distribution and collection centers in CLSCs will remarkably reduce total construction costs. It should be noted that this idea is suitable for industries that hybrid centers are technologically possible to handling the products. In WPC industry, it is possible to utilize hybrid centers in different echelons of the CLSC network. Therefore, we consider hybrid centers for manufacturing-recycling activities as well as hybrid centers for distribution-collection activities.

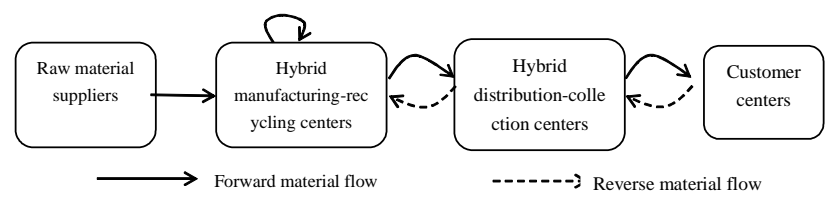

Figure 1. The structure of the considered CLSC network.

In the considered CLSC network for WPC industry, raw materials are purchased from suppliers and are converted to finished products at hybrid manufacturing-recycling centers. It should be noted that in any production process, usually some waste occurs during the process of converting raw material into final products. The advantage of this type of production (WPC products) is that all waste generated during the production process can be re-introduced as a raw material into the cycle. The products manufactured at the factories are sent to the hybrid distribution-collection centers, and from these centers, the customer's request is sent to different areas of the customers. The used products are collected from customers. Also, it is assumed that other WPC products may be collected from customers. The used WPC products are purchased from customers or substituted with new WPC products at hybrid distributioncollection centers. The collected products are shipped to hybrid manufacturing-recycling centers and after crumbling are used as raw material.

The main strategic decisions taken by the proposed model include determination of the number and location of facilities in different echelons of the CLSC network. Also, the optimal values of raw material purchasing, production, transportation, and collection amounts are determined as tactical decisions.

The main assumptions that have been considered in constructing the mathematical model include the following:

- All parameters of the proposed model are considered to be deterministic.

- Transportation is carried out for the delivery of products to customers and the collection of products and other transports are available only by a mode of transportation.

- $\quad$ Some used WPC products are purchased at a reasonable price.

- All facilities in different layers have limited capacity.

- The production of new products and the recovery of defective products are handled in hybrid manufacturingrecycling centers.

- Distribution of new products and collection of recycled products are carried out at hybrid distribution-collection centers.

- The distribution of new products as well as the collection of used products is carried out by hybrid distributioncollection centers and the customer can not directly buy from existing factories.

- Demand is estimated according to the population of provinces.

- There are two types of customers for purchasing used products. Customers which have purchased our products (first group) and customers that have not purchased our products (second group).

- The capacities of suppliers are assumed to be infinite.

In the following the indices, parameters and variables used in the proposed model are described.

Indices

$P \quad$ Set of WPC products $(p=1, \ldots, P)$

$S \quad$ Set of supply center $(s=1, \ldots, S)$

$F \quad$ Set of raw material $(f=1, \ldots, F)$

I Set of hybrid manufacturing-recycling centers $(i=1$, $\ldots, I)$

$J$ Set of hybrid distribution-collection centers $(j=1, \ldots$, $J)$

$K \quad$ Set of customer zones $(k=1, \ldots, K)$

\section{Parameters}

$e_{j} \quad$ Fixed cost of opening hybrid at location $j$

$g_{i} \quad$ Fixed cost of opening hybrid manufacturing-recycling center at location $i$

$c_{a b}$ Transportation cost from location $a$ to location $b$; from $a$ to $b$

$a_{p j}$ Sorting cost of product $p$ in hybrid distribution-collection center $j$

$l_{p i}$ Production cost of product $p$ in hybrid manufacturing-recycling center $i$

$d_{p k}$ Demand of product $p$ for consumer zone $k$

$\alpha_{f p} \quad$ Conversion ratio of raw materials $f$ to product $p$

$\varphi_{f p} \quad$ Conversion ratio of collected used product to raw material $f$

$\beta_{p i} \quad$ Waste percent of product $p$ at hybrid manufacturingrecycling center $i$

$\gamma_{p k} \quad$ Return percentage of recoverable product $p$ collected from the first group of customer $k$ 
$\eta_{p k} \quad$ Return percentage of recoverable product $p$ collected from the second group of customer $k$

$B I_{p i}$ Recycling capacity of hybrid manufacturing-recycling center $i$ for product $p$

$A I_{p i}$ Production capacity of hybrid manufacturing-recycling center $i$ for product $p$

$A J_{p i}$ Storage capacity of hybrid distribution-collection center $j$ for product $p$

$B J_{p i}$ Storage capacity of hybrid distribution-collection center $j$ for the used product $p$

$k x_{p k}$ Cost of purchasing a product $p$ from customer zone $k$

$R c_{p i}$ Cost of recycling the product $p$ at the hybrid manufacturing-recycling center $i$

\section{Decision variables}

$x_{j} \quad 1$, If the hybrid distribution-collection center $j$ is opened; 0, Otherwise

$y_{i} \quad 1$, If the hybrid manufacturing-recycling center $i$ is opened; 0 Otherwise

$w_{p j k}$ Transported amount of product $p$ from hybrid distribution-collection center $j$ to customer zone $k$

$u_{p k j}$ Transported amount of product $p$ from the first group of customer zone $k$ to the hybrid distribution-collection center $j$

$u_{p k j}^{\prime}$ Transported amount of product $p$ from the second group of customer zone $k$ to hybrid distribution-collection center $j$

$b_{f s i}$ Transported amount of raw material $f$ from supply center $s$ to hybrid manufacturing-recycling center $i$

$q_{p i j}$ Transported amount of product $p$ from hybrid manufacturing-recycling center $i$ to hybrid distributioncollection center $j$

$v_{p j i}$ Transported amount of product $p$ from hybrid distribution-collection center $j$ to hybrid manufacturing-recycling center $i$

$b x_{f i}$ Required amount of raw material $f$ in hybrid manufacturing-recycling center $i$

The proposed MILP model:

$$
\begin{aligned}
\operatorname{Min} Z= & \sum_{i=1}^{I} g_{i} y_{i}+\sum_{j=1}^{J} e_{j} x_{j}+\sum_{f=1}^{F} \sum_{s=1}^{S} \sum_{i=1}^{I} c_{s i} b_{f s i} \\
& +\sum_{p=1}^{P} \sum_{i=1}^{I} \sum_{j=1}^{J}\left(l_{p i}+c_{i j}\right) q_{p i j}+\sum_{p=1}^{P} \sum_{j=1}^{J} \sum_{k=1}^{K}\left(a_{p j}+c_{j k}\right) w_{p j k} \\
& +\sum_{p=1}^{P} \sum_{k=1}^{K} \sum_{j=1}^{J}\left(u_{p k j}+u_{p k j}^{\prime}\right)\left(a_{p j}+c_{k j}+k x_{p k}\right) \\
& +\sum_{p=1}^{P} \sum_{j=1}^{J} \sum_{i=1}^{I} v_{p j i}\left(c_{j i}+R c_{p i}\right)+\sum_{p=1}^{P} \sum_{j=1}^{J} \beta_{p i} q_{p i j} R c_{p i}
\end{aligned}
$$

$\sum_{j=1}^{J} w_{p j k} \geq d_{p k} \forall p, k$

$$
\begin{aligned}
& \sum_{k=1}^{I} q_{p i j}=\sum_{k=1}^{K} w_{p j k} \forall p, k \\
& b x_{f i}=\sum_{j=1}^{J} \sum_{p=1}^{P} \frac{1}{\alpha_{f p}} q_{p i j} \forall f, i \\
& b x_{f i}=\sum_{s=1}^{S} b_{f s i}+\varphi_{f} \sum_{p=1}^{P} \sum_{j=1}^{J} v_{p j i}+\sum_{p=1}^{P} \sum_{j=1}^{J} \beta_{p i} q_{p i j} \forall i, f \\
& \sum_{k=1}^{K}\left(u_{p k j}+u_{p k j}^{\prime}\right)=\sum_{i=1}^{I} v_{p j i} \forall p, j \\
& \sum_{j=1}^{J} u_{p k j}=\gamma_{p k} d_{p k} \forall k, p \\
& \sum_{j=1}^{J} u_{p k j}^{\prime}=\eta_{p k} d_{p k} \forall k, p \\
& \sum_{j=1}^{J} v_{p j i}+\sum_{j=1}^{J} \beta_{p i} q_{p i j} \leq B I_{p i} y_{i} \forall i, p \\
& \sum_{j=1}^{J} q_{p i j} \leq A I_{p i} y_{i} \forall i, p \\
& \sum_{i=1}^{I} q_{p i j} \leq A J_{p j} x_{j} \forall p, j \\
& \sum_{k=1}^{K}\left(u_{p k j}+u_{p k j}^{\prime}\right) \leq B J_{p j} x_{j} \forall p, j \\
& w_{p j k}, u_{p k j}, u_{p k j}^{\prime}, b_{f s i}, q_{p i j} \geq 0 \forall i, j, p, s, f, k \\
& x_{j}, y_{i} \in\{0,1\} \forall i, j
\end{aligned}
$$

In the objective function (1), the goal is minimizing total costs, including the fixed cost of opening hybrid manufacturing-recycling centers, the fixed cost of establishing hybrid distribution-collection centers, cost of recycling the products, cost of purchasing a product from a customer for recycling, raw material purchasing costs, transportation and processing costs of forward and reverse material flow. Limitation (2) states that the amount of goods carried from hybrid distribution-collection centers to customer areas should be large or equal to the demand of that customer area. Limitation (3) indicates that the amount of products carried from hybrid manufacturing-recycling centers to hybrid distribution-collection centers is equal to the amount of products carried from hybrid distribution-collection centers to the customer's areas.

Limitation (4) indicates the balance between raw materials in hybrid manufacturing-recycling centers and the quantities of goods carried from these facilities to hybrid distribution-col- 
lection centers. Constraint (5) ensures that the amount of returned goods from the hybrid distribution-collection centers along with the number of waste products produced in the hybrid manufacturing-recycling centers, as well as the amount of raw material carried from the suppliers to the hybrid manufacturing-recycling centers must be equal to the amount of required raw material. Limitation (6) refers to the amount of goods carried from customer areas to hybrid distribution-collection centers, which should be equal to the amount of goods carried from hybrid distribution-collection centers to the hybrid manufacturing-recycling centers.

Constraints (7) and (8) show that some percentage of used products are collected from the first and second groups of customers, respectively. Limitation (9) indicates recycling capacity of hybrid manufacturing-recycling centers for the collected products. Constraint (10) shows production capacity of hybrid manufacturing-recycling centers for the new products. Limitations (11) and (12) indicate the storage capacity of the new products and collected products in hybrid distribution-collection centers, respectively. If a facility is not established its corresponding binary variable will be zero and therefore the related capacity would be zero. Constraints (13) and (14) consider non-negativity and bi-nary conditions for the decision variables.

\section{Computational Results and Discussions}

\subsection{Data Collection}

The used data have been gathered through referring to previous feasibility studies conducted in Iran, WPC manufacturing and transportation companies. After gathering data to show them in a summary form, the ranges of some parameters are shown. Due to space limitation all data are not presented here, but they could be provided upon to request. The most important data have been presented in Supplementary Material.

The demand for the country is 188,700 tons of products, which is presented in Table $\mathrm{S} 1$ for each product and each province (see Supplementary Material). It should be noted that the weight of each door is $80 \mathrm{~kg}$ and the weight of each window is $40 \mathrm{~kg}$. The figures presented in this table are based on feasibility studies conducted by the Ministry of Industry, Mining and Trade of Iran (http://www.mimt.gov.ir/). The fixed costs of establishing the WPC plants and distribution and collection centers are shown in Tables S2 and S3 (see Supplementary Material).

Distance among different provinces of Iran is provided by Ministry of Roads \& Urban Development (http://mrud.ir). Distance are used to calculated transportation costs. Tables $\mathrm{S} 4$ and S5 summarizes the ranges of different parameters used in solving the model (see Supplementary Material). Note that the parameters cab shows the transportation costs between locations $a$ and $b$. These parameters have different values and to show them in a summary form, their ranges are reported.

According to the MILP structure of the proposed model, the CPLEX solver of the GAMS optimization software is used to solve the model.
The number of suppliers of raw materials in this study is considered to be five. In this research, all provinces of Iran have been evaluated, which includes 31 provinces, to determine the optimal locations for establishing hybrid manufacturing-recycling centers and hybrid distribution-collection centers throughout Iran.

In general, the purpose of this research is to determine the number and location of the facilities in the CLSC network, as well as the amount of production and required raw material, and transportation, so that the objective function of the model is minimized and the existing limitations are not compromised.

After solving the model in the software, the optimum value obtained for the objective function is approximately 23,090,557 million Rials. According to the achieved results, five provinces including: Western Azerbaijan, Kohkiluyer and Boyer Ahmad, Golestan, Gilan, Mazandaran and Yazd are selected for opening hybrid manufacturing-recycling centers. Also, solving the model shows that the twelve provinces indicated in Table 1 and Figure 2 are optimum locations for establishing hybrid distribution-collection centers.

Table 1. The Best Locations for Opening Hybrid Distributioncollection Centers

\begin{tabular}{llll}
\hline Row & Province & Row & \multicolumn{1}{c}{ Province } \\
\hline 1 & Western & 7 & $\begin{array}{l}\text { Kohkiluyer and Boyer } \\
\text { Ahmad }\end{array}$ \\
& Azerbaijan & & Golestan \\
2 & Ilam & 8 & Gilan \\
3 & Bushehr & 9 & Lorestan \\
4 & Chahar Mahal & 10 & \\
& Bakhtiari & 11 & Mazandaran \\
5 & southern Khorasan & 11 & Yazd \\
6 & Kerman & 12 & \\
\hline
\end{tabular}

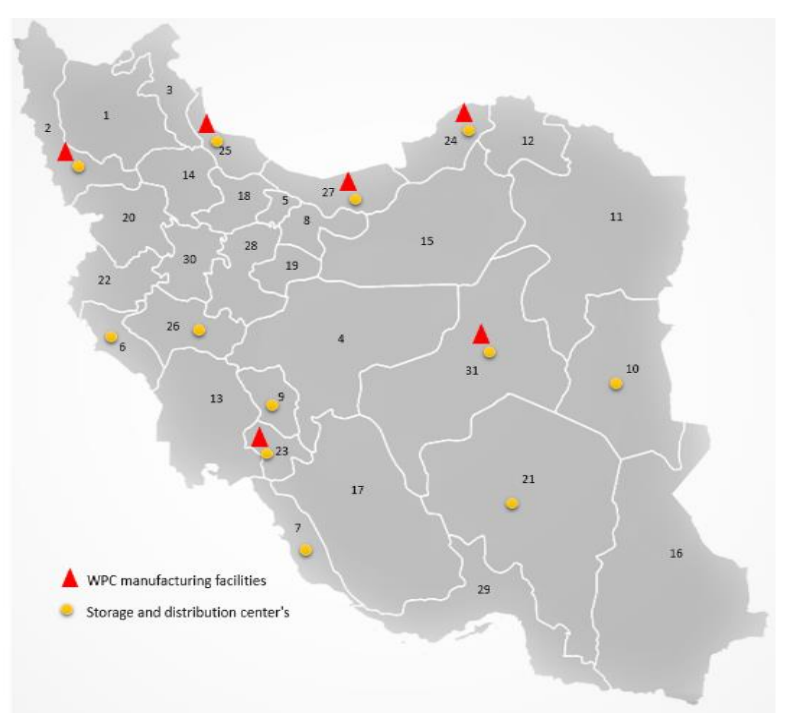

Figure 2. Locations for opening manufacturing-recycling center \& distribution-collection centers.

As it is shown in Table 1 and Figure 2 the proposed model prefers to open more distribution-collection centers than man- 
Table 2. Production Rate at Selected Factories

\begin{tabular}{llll}
\hline Row & Province & Window & Door \\
\hline 1 & Western Azerbaijan & 344,000 & 258,000 \\
2 & Kohkiluyer and Boyer Ahmad & 352,000 & 264,000 \\
3 & Golestan & 271,000 & 203,250 \\
4 & Gilan & 320,000 & 240,000 \\
5 & Mazandaran & 328,000 & 246,000 \\
6 & Yazd & 272,000 & 204,000 \\
\hline
\end{tabular}

Table 3. The Optimum Amount of Required Raw Material (Tons)

\begin{tabular}{llll}
\hline Row & Province & Wood Flour & Polymer materials \\
\hline 1 & Western Azerbaijan & 20,100 & 17,116 \\
2 & Kohkiluyer and Boyer Ahmad & 21,243 & 16,839 \\
3 & Golestan & 16,948 & 12,370 \\
4 & Gilan & 19,522 & 15,098 \\
5 & Mazandaran & 20,137 & 15,349 \\
6 & Yazd & 16,842 & 12,585 \\
\hline
\end{tabular}

Table 4. The Amount of Raw Material Obtained from Recycled Materials

\begin{tabular}{lll}
\hline Row & Province & Wood Flour(Tons) \\
\hline 1 & Western Azerbaijan & 1,926 \\
2 & Kohkiluyer and Boyer Ahmad & 3,286 \\
3 & Golestan & 3,686 \\
4 & Gilan & 3,397 \\
5 & Mazandaran & 3,728 \\
6 & Yazd & 3,371 \\
\hline
\end{tabular}

ufacturing-recycling centers. These results could be explained due to lower opening costs distribution-collection centers and decreasing transportation costs. Also, the amount of demand in different provinces has a great impact on the locations of facilities.

In Iran, population density is higher in the north and northwest of the country. Therefore, most of the established plants are located in these areas. These provinces have been selected because of their proper capacity for storage of products and waste, as well as their proximity to provinces that have higher demand. West Azarbaijan province has been selected because of its considerable demand, as well as because of its location between the two provinces of East Azarbaijan and Kurdistan (which are more in demand than the surrounding provinces). Therefore, it can easily eliminate the demand of the surrounding provinces, with transportation costs and lower construction costs. The three provinces of Golestan, Gilan and Mazandaran are selected because of their proximity to the province of Tehran (the most populous province of Iran with the highest demand). These provinces themselves are in high demand and have a lower fixed cost, which has a high storage capacity compared to the surrounding provinces. Finally, Yazd province, which is located between the two densely populated areas of Isfahan and Khorasan Razavi, can respond to their demand by cost. Therefore, the established locations are justified.

About the selection of distribution and collection centers to reduce shipping costs, the model chooses the construction of distribution and collection centers in the same provinces where the plants were built. Where the capacity of the distribution and collection centers is not met by the amount of demand or the amount of waste purchased, it chooses the provinces around the factory with lower costs and good capacity.

Table 2 shows the production rate of each product in the factories. It should be noted that, as noted earlier, the weight of each door is 0.08 tons and the weight of each window is 0.04 tons. So, each ton contains a total of 17.5 doors and windows.

According to Table 2, a total of 1,887,000 windows (or 75,480 tons) and 1,415,250 doors (or 113,220 tons) are produced, which is equal to the demand for this product.

Another important decision taken by the proposed model is the required raw materials. Table 3 illustrates the amount of raw materials required in opened hybrid manufacturing-recycling centers for satisfying the demand of final products.

According to Table 3, total amount wood floor and polymer material required for producing doors and windows are 114,792 and 89,357 tons, respectively. Table 4 illustrates the amount of raw material obtained from recycling the used products.

About the raw materials used in the production of products, it should be added that 19,394 tons of the wood flour is supplied from recycling the used products. This amount constitutes about 17 percent of total wood flour required for producing the products.

Table 5 shows the share of different costs in the objective function, like the fixed cost of building a factory and the cost 
Table 5. Different Costs in the Objective Function

\begin{tabular}{ll}
\hline Cost & Value (Million Rials) \\
\hline Fixed cost of opening WPC manufacturing & $1,022,854$ \\
Fix cost of WPC distribution-collection center & 123,295 \\
Production cost & $18,870,000$ \\
Sorting cost for products & $1,320,900$ \\
Sorting cost for waste & 396,270 \\
Recycling cost & 467,976 \\
Buying waste cost & 622,710 \\
Transportation cost (forward flow) & 241,128 \\
Transportation cost (reverse flow) & 25,424 \\
\hline
\end{tabular}

Table 6. Locations and Objective Function Changes of Facilities under Demand (D) Changes

\begin{tabular}{llllllll}
\hline & $0.80 \times \mathrm{D}$ & $0.90 \times \mathrm{D}$ & $0.95 \times \mathrm{D}$ & $1 \times \mathrm{D}$ & $1.05 \times \mathrm{D}$ & $1.10 \times \mathrm{D}$ & $1.20 \times \mathrm{D}$ \\
\hline Objective function & $18,481,590$ & $20,842,048$ & $21,956,006$ & $23,090,557$ & $24,260,470$ & $25,429,317$ & $27,724,004$ \\
wpc manufacturing- & $3,23,24$, & $2,3,9,24$, & $2,3,9,24$, & $2,23,24$, & $2,5,23$, & $2,3,9,24$, & $1,2,21,23$, \\
recycling centers & 27,31 & 27,31 & 27,31 & $25,27,31$ & $24,25,27$ & $26,27,31$ & $24,25,27$ \\
wpc distribution- & $3,7,10,21$, & $2,9,10,21$, & $2,6,9,10,21$, & $2,6,7,9,10,21$ & $2,6,7,9,10,12$ & $2,3,9,10,21$, & $2,6,7,9,10,15$, \\
collection center & $23,24,25$, & $23,24,25$, & $23,24,25$, & $, 23,24,25$, & $, 18,20,23,24$, & $22,23,24,25$, & $18,20,21,22,2$ \\
& $26,27,31$ & $26,27,31$ & $26,27,31$ & $26,27,31$ & $25,26,27,31$ & $26,27,31$ & $3,24,25,27,31$ \\
\hline
\end{tabular}

Table 7. Locations and Objective Function Changes of Facilities under Transportation Cost (C) Changes

\begin{tabular}{llllllll}
\hline & $0.80 \times \mathrm{C}$ & $0.90 \times \mathrm{C}$ & $0.95 \times \mathrm{C}$ & $1 \times \mathrm{C}$ & $1.05 \times \mathrm{C}$ & $1.10 \times \mathrm{C}$ & $1.20 \times \mathrm{C}$ \\
\hline Objective function & $23,035,372$ & $23,062,973$ & $23,076,774$ & $23,090,557$ & $23,103,475$ & $23,116,389$ & $23,142,218$ \\
wpc manufacturing- & $2,3,9$, & $2,3,9$, & $2,3,9$, & $2,23,24$, & $2,23,24$, & $2,23,24$, & $2,23,24$, \\
recycling centers & $24,27,31$ & $24,27,31$ & $24,27,31$ & $25,27,31$ & $25,27,31$ & $25,27,31$ & $25,27,31$ \\
wpc distribution- & $2,7,9,10$, & $2,7,9,10$, & $2,7,9,10$, & $2,6,7,9$, & $2,7,9,10$, & $2,7,9,10$, & $2,7,9,10$, \\
collection center & $15,21,23$, & $15,21,23$, & $15,21,23$, & $10,21,23$, & $20,21,23$, & $20,21,23$, & $20,21,23$, \\
& $24,25,26$, & $24,25,26$, & $24,25,26$, & $24,25,26$, & $24,25,26$, & $24,25,26$, & $24,25,26$, \\
& 27,31 & 27,31 & 27,31 & 27,31 & 27,31 & 27,31 & 27,31 \\
\hline
\end{tabular}

Table 8. Objective Function Changes under Production Cost (L) Changes

\begin{tabular}{llllllll}
\hline & $0.80 \times \mathrm{L}$ & $0.90 \times \mathrm{L}$ & $0.95 \times \mathrm{L}$ & $1 \times \mathrm{L}$ & $1.05 \times \mathrm{L}$ & $1.10 \times \mathrm{L}$ & $1.20 \times \mathrm{L}$ \\
\hline Objective function & $19,316,557$ & $21,203,557$ & $22,147,057$ & $23,090,557$ & $24,034,057$ & $24,977,557$ & $26,864,557$ \\
\hline
\end{tabular}

of building distribution and collection centers, production and transportation costs and so on.

Therefore, the total recycling cost is $1,512,380$ million Rials, which includes sorting cost for waste, recycling cost, buying waste cost and transportation cost (reverse flow).

It should be noted that the producing cost is the highest possible cost, can be reduced by adopting suitable policies such as lean production techniques. For example, by encouraging customers to sell their useless doors and windows, the need to buy raw wood flour is significantly reduced.

\subsection{Sensitivity Analysis}

In the next step, the sensitivity analysis is carried out on the most important parameters of the proposed model to evaluate the behavior of the model respect to changes of these parameters.

Figure 3 shows changes of the objective function from the value of $20 \%$ lower to $20 \%$ greater than nominal value of related parameters. Table 6 shows the locations that are selected in the event of an increase and decrease in demand. By changing this parameter, the selected optimized locations change in some places. As demand increases, the capacity of some selected locations no longer responds to that demand. Therefore, places that have more capacity replace some places, or are added to previous locations. Also, by reducing demand, the capacity of some locations selected by the model is greater than the capacity required. Therefore, sites that simultaneously reduce the objective function and also respond to the existing demand is selected. Therefore, the sensitivity of the model to the demand parameter is very high and it is better to consider the uncertainty of demand parameter in the future.

Table 7 shows the variation of the transportation cost and its impact on the objective function and the selected locations. As can be seen, the increase and decrease of this parameter does not have a significant effect on the value of the objective function. By increasing the transportation cost, the locations selected for the factory construction will not change. But the distribution and collection center changes from Ilam province to Kurdistan province. With this change, the cost of transportation 
from factory to distribution and collection centers is reduced, but other shipping costs are rising. If this change did not occur, transportation costs would rise further. By reducing transporttation costs, locations 23 and 25 will change to locations 3 and 9 to build the plant. And the 6th place for the construction of the distribution and collection centers will change to the 15 th place. With these changes, the cost of transportation of raw materials from the supplier to the factory increases, but the total transportation costs are reduced in advance. If that does not change the location, it will not be reduced to this size.

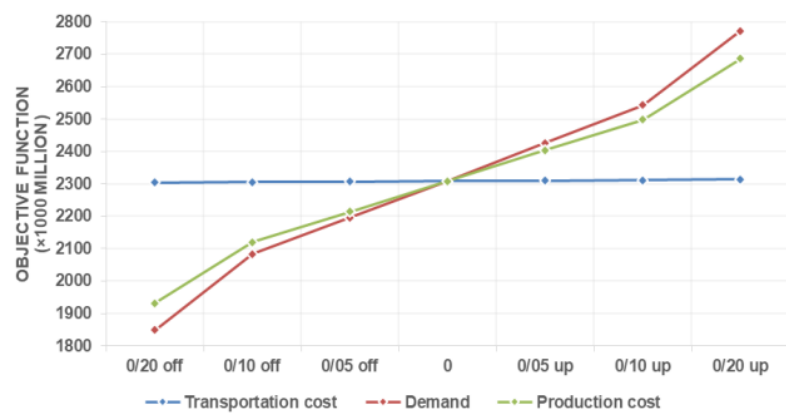

Figure 3. Sensitivity analysis on important parameters.

Table 8 show the amount of changes in the objective function by increasing and decreasing production cost parameter. By changing this parameter, the selected locations do not change for factories and distribution and collection centers.

According to Figure 3 and Tables 6, 7, and 8 among these three parameters, the most important parameter is demand, since in addition to the very high impact on the objective function, it is also effective in the number of optimal locations. Although transportation cost affects to the factory and distribution and collection centers locations, its impact on the objective function is very low. Therefore, the cost of post-demand production has the greatest impact on target performance. Finally, the shipping cost parameter has the least effect on the objective function.

\section{Conclusion}

Considering the importance of WPC products in environmental protection, in this research, a mixed-integer linear programming (MILP) model is proposed to construct the CLSC network for WPC industry. Choosing the location of facilities and distribution centers, as well as the amount of transport between different locations, are the most important decisions in CLSC management. The proposed model is aimed to minimize the total costs including production, transportation, collection, and recycling costs subject to various real limitations. The goal of this research is to optimize strategic decisions such as the number and locations of WPC production and recycling centers, distribution and collection centers as well as tactical decisions such as the required raw material, production, distribution-collection amounts in the forward and reverse sides of the proposed CLSC network. After solving the model, six provinces including Western Azerbaijan, Kohkiluyer and Boyer
Ahmad, Golestan, Gilan, Mazandaran and Yazd have been selected for the construction of WPC manufacturing and recycling centers, and 12 provinces have been selected for the construction of distribution and collection centers. Also, the optimum material flow is determined with the structure of the CLSC network. Finally, sensitivity analysis is performed to evaluate the behavior of the model with respect to changes of important parameters. The results show that the model is sensitive to changes in demand and shipping costs, and it is better to consider demand uncertainty and shipping costs in future studies.

Among the issues that can be studied as future research, studying the model under uncertainty and using fuzzy theory or stochastic programming methods is an efficient future research. The proposed model could be developed for multi-period condition and different modes of transportation can be added to the model. Also, two objective functions for the problem can be defined, one of which is the type of maximization of social welfare, and the other is to minimize environmental impact.

Acknowledgments. The authors would like to thank the associate editor and anonymous reviewers for their insightful and constructive comments.

\section{References}

Lee, H.L. (2002). Aligning supply chain strategies with product uncertainties, Calif. Manage. Rev., 44(1), 105-119. https://doi.org/1 $0.2307 / 41166135$

Cruz-Rivera, R. and Ertel, J. (2009). Reverse logistics network design for the collection of end-of-life vehicles in Mexico, Eur. J. Oper. Res., 196(1), 930-939. https://doi.org/10.1016/j.ejor.2008.04.041.

Kara, S.S. and Onut, S. (2010). A two-stage stochastic and robust programming approach to strategic planning of a reverse supply network: The case of paper recycling, Expert Syst. Appl., 37(9), 6129-6137. https://doi.org/10.1016/j.eswa.2010.02.116.

Govindan, K., Soleimani, H., and Kannan, D. (2015). Reverse logistics and closed-loop supply chain: A comprehensive review to explore the future. Eur. J. Oper. Res., 240(3), 603-626. https://doi.org/10. 1016/j.ejor.2014.07.012.

Moyes, H. (2000). Method of manufacturing a molded door skin from a wood composite, door skin produced therefrom, and door manufactured therewith. U.S. Patent No. 6,073,419.

Hanssmann, F. and Hess, S.W. (1960). A linear programming approach to production and employment scheduling, Manag. Sci., 1, 46-51. https://doi.org/10.1287/mantech.1.1.46.

Von Lanzenauer, C.H. (1970). Production and employment scheduling in multistage production systems, Nav. Res. Logistics Q., 17(2), 193-198. https://doi.org/10.1002/nav.3800170206.

Fleischmann, M., Beullens, P., Bloemhof-Ruwaard, J., and Van Wassenhove, L. (2001). The impact of product recovery on logistics network design, Prod. Oper. Manag., 10, 156-173. https://doi.org/1 0.1111/j.1937-5956.2001.tb00076.x.

Fleischmann, M., van Nunen, J.A.E.E., and Grave, B. (2003). Integrating closed-loop supply chains and spare-parts management at IBM, Interfaces, 33 (4), 44-56. https://doi.org/10.1287/inte.33.6.44. 25189.

Chen, C.L. and Lee, W.C. (2004). Multi-objective optimization of multi-echelon supply chain networks with uncertain product demands and prices, Comput. Chem. Eng., 28(6), 1131-1144. https://doi.org/ 10.1016/j.compchemeng.2003.09.014.

Beamon, B.M. and Fernandes, C. (2004). Supply chain network 
configuration for product recovery, Prod. Plann. Control, 15(1), 270-281. https://doi.org/10.1080/09537280410001697701.

Sheu, J.B., Chou, Y.H., and Hu, C.C. (2005). An integrated logistics operational model for green-supply chain management, Trans. Res. 41, 287-313. https://doi.org/10.1016/j.tre.2004.07.001

Uster, H., Easwaran, G., Akcali, E., and Cetinkaya, S. (2007). Benders decomposition with alternative multiple cuts for a multiproduct closed-loop supply chain network design model, Nav. Res. Logistics, 54, 890-907.https://doi.org/10.1002/nav.20262.

Listes, O. (2007). A generic stochastic model for supply-and-return network design, Comput. Chem. Eng., 34, 417-442.https://doi.org/ 10.1016/j.cor.2005.03.007.

Ramudhin, A., Chaabane, A., and Paquet, M. (2010). Carbon market sensitive sustainable supply chain network design, Int. J. Manag. Sci. Eng. Manag., 5(1), 30-38. https://doi.org/10.1080/17509653. 2010.10671088

Paksoy, T., Özceylan, E., and Weber, G.W. (2010). A multi objective model for optimization of a green supply chain network, AIP Conference Proceedings, 1239(1), AIP. https://doi.org/10.1063/1.345 9765.

Paksoy, T., Bektaş, T., and Özceylan, E. (2011). Operational and environmental performance measures in a multi-product closedloop supply chain, Transp. Res. E, 47(4), 532-546. https://doi.org/ 10.1016/j.tre.2010.12.001.

Chaabane, A., Ramudhin, A., and Paquet, M. (2012). Design of sustainable supply chains under the emission trading scheme, Int $J$. Prod. Econ., 135(1), 37-49. https://doi.org/10.1016/j.ijpe.2010.10. 025.

Özkır, V. and Başlıgil, H. (2013). Multi-objective optimization of closed-loop supply chains in uncertain environment, $J$ Cleaner Prod., 41, 114-125. https://doi.org/10.1016/j.jclepro.2012.10.013.

Talaei, M., Farhang Moghaddam, B., Pishvaee, M.S., bozorgi-Amiri, A., and Gholamnejad, S. (2016). A robust fuzzy optimization model for carbon-efficient closed-loop supply chain network design problem: a numerical illustration in electronics industry, J. Cleaner Prod., 113, 662-673. https://doi.org/10.1016/j.jclepro.2015.10.074

Hassanzadeh Amin, S., Zhang, G., and Akhtar, P. (2017). Effects of uncertainty on a tire closed-loop supply chain network, Expert Syst. Appl., 73, 82-91. https://doi.org/10.1016/j.eswa.2016.12.024.

Pishvaee, M.S., Jolai, F., and Razmi, J. (2009). A stochastic optimization model for integrated forward/reverse supply chain network design, J. Manuf. Syst., 28, 107-114. https://doi.org/ 10.1016/j.jmsy.2010.05.001. 